\title{
The sexual and parenting rights of people with physical and psychical disabilities: attitudes of Italians and socio-demographic factors involved in recognition and denial
}

\author{
Simona Gabriella Di Santo ${ }^{1,2,}$, Margherita Colombo ${ }^{3^{*}}$, Marco Silvaggi ${ }^{4}$, Giorgia Rosamaria Gammino ${ }^{5}$, Valentina \\ Fava $^{6}{ }^{6}$ Chiara Malandrino ${ }^{6}$, Chiara Nanini ${ }^{7}$, Cristina Rossetto ${ }^{8}$, Sara Simone ${ }^{9}$, and Stefano Eleuteri ${ }^{10,11}$
}

\author{
IRCCS Fondazione Santa Lucia via Ardeatina 30600179 Roma; s.disanto@hsantalucia.it \\ Italian Association of Applied Sexology and Psychology (AISPA) via Marostica 3520146 Milano; \\ s.disanto@hsantalucia.it \\ 3 Superior School of Clinical Sexology of Turin Via Unione Sovietica 33510135 Torino; mar- \\ gher-c79@libero.it \\ $4 \quad$ Institute of Clinical Sexology (ISC) Via Savoia 7800198 Roma; m.silvaggi@gmail.com \\ 5 Italian Center of Sexology (CIS) Via Col del Rosso 735141 Padova; g.r.gammino@gmail.com \\ 6 Research group for sexology. Via S. Sofia 7895123 Catania; valentinafavamp4@yahoo.it ; \\ chiaramalandrino@yahoo.it \\ 7 Interdisciplinary Centre for Research and Training in Sexology (CIRS) Via Angelo Ceppi di Bairolo 1/8 \\ 16126 Genova; chiarananini@virgilio.it \\ 8 Study Center for Affective and Sexual Disorders Treatment (DAS) Via G.T. Invrea 20/2 16129 Genova; \\ cristinarossetto@icloud.com \\ $9 \quad$ Institute of Research and training (IRF) Via Luigi Alamanni 2350123 Firenze; sarasimone77@hotmail.com \\ 10 World Association of Sexual health; stefano.eleuteri@uniroma1.it \\ 11 Faculty of Medicine an Psychology, Sapienza University of Rome; stefano.eleuteri@uniroma1.it \\ * Correspondence: SGDS: s.disanto@hsantalucia.it ; Tel.: +39 0651501177 \\ MC: margher-c79@libero.it; Tel.: +39 3471041270
}

\begin{abstract}
The aims of this study were: (1) to analyze the level of agreement of a sample of Italian people with the rights of people with physical and psychical disabilities (PwPHDs and PwPSYDs) to have satisfying sexuality, to marry, to adopt a child; (2) to inquire if PwPSYDs were subject to less recognition than PwPHDs; (3) to verify if socio-demographic characteristics, such as age, sex, education, occupation, geographical origin, relational status, sexual orientation, and religiosity, associated with being against these sexual and parenting rights (SPRs). An online anonymous questionnaire inquired the level of agreement or disagreement with statements regarding the SPRs of PwPHDs and PwPSYDs. 973 participants, aged 18 - 84 years (71.1\% females) were considered for analyses; At least 7 out of 10 participants declared in favor of the SPRs of PwPHDs, while the SPRs of PwPSYDs were always subjected to higher underrecognition. Religiosity almost invariably associated to being against the SPRs of PwDs. Being male, of higher age and lower education also associated with lower recognition. A better identification of the less tolerant respondents and of the less recognized categories may allow for specific strategies for promoting the recognition of the SPRs for PwDs.
\end{abstract}

Keywords: sexual rights, physical disabilities, psychical disabilities, sexual minorities, societal attitudes

\section{Introduction}

More than $15 \%$ of the world's population is affected by disabilities, including physical and sensory impairments, developmental and intellectual disabilities and psychosocial disabilities[1]. Disabilities are defined by the UN Convention on the Rights of Persons with Disabilities (UNCRPD) as the presence of long-term physical, mental, intellectual or sensory impairments, which in interaction with various barriers may hinder their full and ef- 
fective participation in society on an equal basis with others[2]. Disabilities, therefore are not caused by the impairments themselves, but rather by the presence of barriers in the physical environment, access to information and education, laws and norms, services and societal beliefs and behaviors[3].

One main barrier that people with disabilities (PwDs) - and in particular those with psychical and intellectual impairments - are still forced to face, concerns the full realization of their sexual and parenting rights (SPRs). SPRs are today considered fundamental human rights, and their violation constitutes a violation of the rights to equality, non-discrimination, dignity and health[4]. The SPRs of PwDs concerning marriage, family, parenthood, relationships, fertility, access to information and sexual and reproductive health services and freedom from exploitation and abuse are supported at the institutional level[1,2] Despite this, the sexual rights of people with disabilities struggle to be recognized in societies, often due prejudices and stereotypes. Stereotypes associated with PwDs presume that they are childlike, not sexually attractive, with underdeveloped or abnormal sexual desires, and maladjusted to any kind of sexual expression[5]. "Myths" about disability include prevalent and related false beliefs, such as the "myth of physical perfection'[6] which considers PwDs as not sexually attractive; the 'myth of asexuality'[7,8], which elicit perceptions of vulnerability, childlike innocence, and dependency, and justifies the presumption of an absence of affective and erotic experiences in PwDs, who are seen as holy innocents disinterested in sex; the 'fucking ideology[7] which considers 'sex' synonymous with heterosexual penetrative intercourse with male-dominant sex positions, and it makes it difficult to imagine PwDs able to have sex, because of their impairments. It is hypothesized that these myths and stereotypes influence the attitudes of people in general and, specifically, of parents or caregivers who care for PwDs. As a result, PwDs face a myriad of demand and supply-side barriers to accessing sexual and reproductive healthcare[9,10].

Evidence also shows that attitudes towards PwDs also differ by type of disability, with those with more visible disabilities[3] or people with psychical disabilities (PwPSYDs) often facing greater discrimination than persons with physical disabilities (PwPHDs)[11]. PwPSYDs are deemed unable to provide valid consent[12], to marry or have children[13], or, far from being angelic, to be hypersexual, unable to control theirselves, devoid of any inhibition, irresponsible and sometimes perverse[14]. Sexual stigma disfavors opportunities for intimate relationships, procreation, sexual education and sexual health. Sexuality is often discouraged and inaccessible to many adults with disabilities. PwDs often lack safe, private places to engage in partnered or individual sexual activities, and reproductive and parenting rights of PwDs, and in particular for PwPSYDs are often viewed negatively by family members, service providers, and the general community[15,16]. Moreover, PwDs are particularly at risk of coercion or of undergoing sterilization or contraceptive procedures, such as intrauterine device (IUD) insertion without their free and fully informed choice and consent. This is especially the case for women with major or multiple impairments or with PSYDs[17]

Some authors tried to inquire which personal characteristics of the population affect attitudes regarding sexuality in PwDs, with inconsistent results, plausibly due to methodological and sample differences. Some studies suggest an effect of age, with older people expressing less accepting positions[18-20], while others failed to find an association between acceptance and age[21,22]. Similarly, while some evidence exist that females displayed more positive attitudes related to sex and disability[22,23], others revealed that males held more liberal opinions [24] and one showed no relationship between gender and attitude towards sexuality[20]. As regards education, some studies revealed an association between higher levels of instruction and more positive attitudes[25], while others showed no relationship [21,22,26]. Attitudes towards sexuality in PwDs may also vary due to beliefs associated with cultural origin $[3,27,28]$ and religion with more religious people tending to hold more conservative opinions [25]. However, most research on attitudes towards the SPRs of PwDs have engaged primarily their fam- 
ily members, supporting staff or university students, while a few updated studies enrolled samples from the general population[3,27,29].

In Italy, serious issues of prejudice and discrimination against minorities exist, to the point that a bill was recently proposed in Parliament seeking to punish acts of discrimination and incitement to violence against gay, lesbian, transgender people and PwDs[30]. The so-called "Zan Law", after being approved in the Chamber of Deputies, was recently rejected in the Senate[31]. This refusal immediately provoked several street demonstrations in the main Italian squares, in which thousands of people took part[32]. Indeed, even if, apparently, Italians would be mostly in favor of granting more rights to minorities, our previous study also indicated that SPRs are less recognized in minorities, such as LGB people[33]. As far as we know, no recent research in Italy inquired the societal level of agreement with the SPRs of PwPHDs and PwPSYD, or the socio-demographic predictors of unfavorable attitudes towards reducing inequalities.

The aim of this study was therefore to analyze the level of agreement of the Italian general population with the right of PwPHDs and PwPSYDs to have satisfactory sexuality, to marry and to adopt a child, and to evaluate whether the SPRs of PwPSYDs were subject to less recognition, compared to PwPHDs. A further objective was to better understand which socio-demographic characteristics of Italian people significantly associated with lower agreement with the SPRs for PwPHDS and PwPSYDs.

\section{Materials and Methods}

\section{Study design and description}

The data reported in this paper is extracted from a larger, original study which cross-sectionally investigated attitudes of Italian people regarding the right of particular minorities or demographic categories (i.e. heterosexual, homosexual, bisexual and transsexual men, women or couples; PwPHDs; PwPSYDs, minors; seniors; sex-workers) to have satisfying sexuality, to marry, to adopt children, to be hired for any job and to be free to live their sexuality[34].

The study was approved by the Scientific Committee of the Italian Federation of Scientific Sexology (FISS) and carried out in cooperation between the Youth Section of FISS (FISS Youth) and the Youth Initiative Committee of the World Association of Sexual Health (WAS YIC). An internet-based anonymous questionnaire was developed with Google Forms (Google LLC, Mountain View, CA, USA) to collect information related to socio-demographic data of respondents and level of agreement with statements related to the abovementioned SPRs.

The questionnaire was distributed through the main social media by all the authors and by colleagues affiliated with their associations, through a snowball sampling approach, and published on the website of the Italian Federation of Scientific Sexology (www.fissonline.it). The first page of the form presented the proponent Institutions, explained the rationale, objectives and contents of the survey, and advised that the survey was reserved exclusively for people aged 18 or over. 'I agree' or 'I do not agree' options on the first page of the questionnaire were used in place of a signature, to provide informed consent. People who did not accept to participate were redirected to the last page of the form and thanked for their potential interest, while those who accepted accessed the survey.

\section{Inclusion/exclusion criteria}

The questionnaire was designed to be proposed to the entire Italian adult population. Therefore, criteria for participation were having reached the age of majority, in accordance with Italian laws and being born and resident in Italy.

Specific contents of the questionnaire

Two main kinds of information were considered: 
(a) socio-demographic information: age in years (categorized in three groups of comparable size); biological sex ('female', 'male'); education (categorical question which included all obtainable levels of Italian education and which was recoded into 'undergraduate', 'graduate', and 'post-graduate'); region of origin (open question, which was recoded in coming from 'North', 'Center' or 'South-Islands'); occupational status ('student', 'employed', or 'unemployed/retired'); occupation (open question, which was recoded in 'healthcare worker' including doctors, psychologists, nurses and other health professionals and 'other profession'), sexual orientation (completely heterosexual, mostly heterosexual, bisexual, mostly homosexual and completely homosexual, which was recoded in 'completely heterosexual' or 'not-completely heterosexual'); relational status (open question, which was recoded in 'single', 'in a committed relationship', 'cohabiting with a partner', 'married'); religiosity ('non-believer', 'believer', 'practicing'); kind of religion (multiple choice with free field to enter non-prefilled data).

(b) the level of agreement with the right for PwPHDs, and PwPSYDs to have satisfying sexuality, to marry and to adopt children, coded on a 6-point likert-type scale, $(1=$ complete disagreement; 2 = moderate disagreement; 3 = mild disagreement; 4 = mild agreement; 5 = moderate agreement; 6 = complete agreement). To prompt to a stance, it was not possible to express intermediate opinions between agreement and disagreement or to avoid answering one or more questions.

\section{Statistical analyses}

All data transformations and analyses were performed with IBM SPSS version 20 (SPSS Inc. Chicago, IL, USA). Descriptive analyses included calculation of the mean \pm standard deviations for continuous variables, and absolute frequencies and percentages for categorical ones. The Shapiro-Wilk test was performed in order to evaluate the normality of distributions.

Since answers to most questions about SPRs were highly skewed towards higher scores, the Wilcoxon matched pairs test was used to compare, the levels of agreement with the right of PwPHDs and PwPSYDs to each right.

Multiple ordinal regression models failed to respect the assumption of proportional odds, due to a large number of empty cells. Therefore, answers to questions related to the SPRs were dichotomized (a score of 1, 2 or 3 was classified as "disagreement" and a score of 4, 5, 6 as "agreement"). Then, univariate and multiple binary logistic regression analyses were conducted to identify those socio-demographic variables which associated with "agreement" with each SPRs for PwPHDs and PwPSYDs, taking "disagreement" as a reference. Values were expressed as odds ratio (OR) and 95\% confidence intervals (95\% CI).

In order to exclude multicollinearity, the Variance Inflation Factor (VIF) was calculated for each predictor. Dummy variables were obtained from non-dichotomous ones and calculated by selecting for reference the most prevalent category. A VIF greater than 2.5 (which corresponds to an $\mathrm{R}^{2}$ of .60) was considered indicative of multicollinearity.

The level of significance was established at 95\% $(\mathrm{p}<0.05)$ for all statistical analyses.

\section{Results}

\subsection{Descriptives}

One thousand and seven out of 1015 people who had accessed the questionnaire provided informed consent to the research. Of these, 34 (3.4\%) were excluded from further analyses because they were not born, or did not live in Italy.

The analyzed sample was therefore composed of 973 participants, aged between 18 and 84 years (mean age: $35.5 \pm 11.7$; median age: 33.0 ). Demographics are shown in detail in table 1 . 
Most participants were female (71.1\%) and people under 40 years of age $(70.5 \%)$; middle-aged people and seniors (people over 50) represented $12.4 \%$ of the sample. Six-hundred and forty-one (65.9\%) were graduates and post-graduates; $21.9 \%$ of the sample consisted of healthcare workers (34.3\% of employed). Four-hundred and eighty-two out of 509 participants declaring themselves non-atheists were catholics $(94.6 \%)$, therefore, due to the low presence of non-catholic responders, 'kind of religion' was excluded from potential predictors of 'agreement'.

Table 1. Descriptive statistics.

\begin{tabular}{|c|c|c|}
\hline Sample Characteristics & Variable levels & Frequencies (\%) \\
\hline \multirow[t]{2}{*}{ Sex } & Male & $281(28.9)$ \\
\hline & Female & $692(71.1)$ \\
\hline \multirow[t]{3}{*}{ Age } & $18-29$ & $348(35.8)$ \\
\hline & $30-39$ & $338(34.7)$ \\
\hline & 40 or more & $287(29.5)$ \\
\hline \multirow[t]{3}{*}{ Provenience } & North & $390(40.1)$ \\
\hline & Center & $314(32.3)$ \\
\hline & South and Islands & $269(27.6)$ \\
\hline \multirow[t]{3}{*}{ Education } & Undergraduate & $332(34.1)$ \\
\hline & Graduate & $391(40.2)$ \\
\hline & Post-graduate & $250(25.7)$ \\
\hline \multirow[t]{3}{*}{ Occupation } & Student & $206(21.2)$ \\
\hline & Employed & $620(63.7)$ \\
\hline & Unemployed or retired & $147(15.1)$ \\
\hline \multirow[t]{4}{*}{ Relational status } & Single & $285(29.3)$ \\
\hline & In a committed relationship & $260(26.7)$ \\
\hline & Cohabiting with partner & $190(19.5)$ \\
\hline & Married & $238(24.5)$ \\
\hline \multirow[t]{3}{*}{ Religiosity } & Atheist/agnostic & $464(47.7)$ \\
\hline & Believer & $361(37.2)$ \\
\hline & Churchgoer & $148(15.2)$ \\
\hline \multirow[t]{2}{*}{ Sexual orientation } & Heterosexual & $730(75.0)$ \\
\hline & $\begin{array}{l}\text { Not-completely heterosexual, } \\
\text { homosexual, bisexual or queer }\end{array}$ & $243(25.0)$ \\
\hline
\end{tabular}




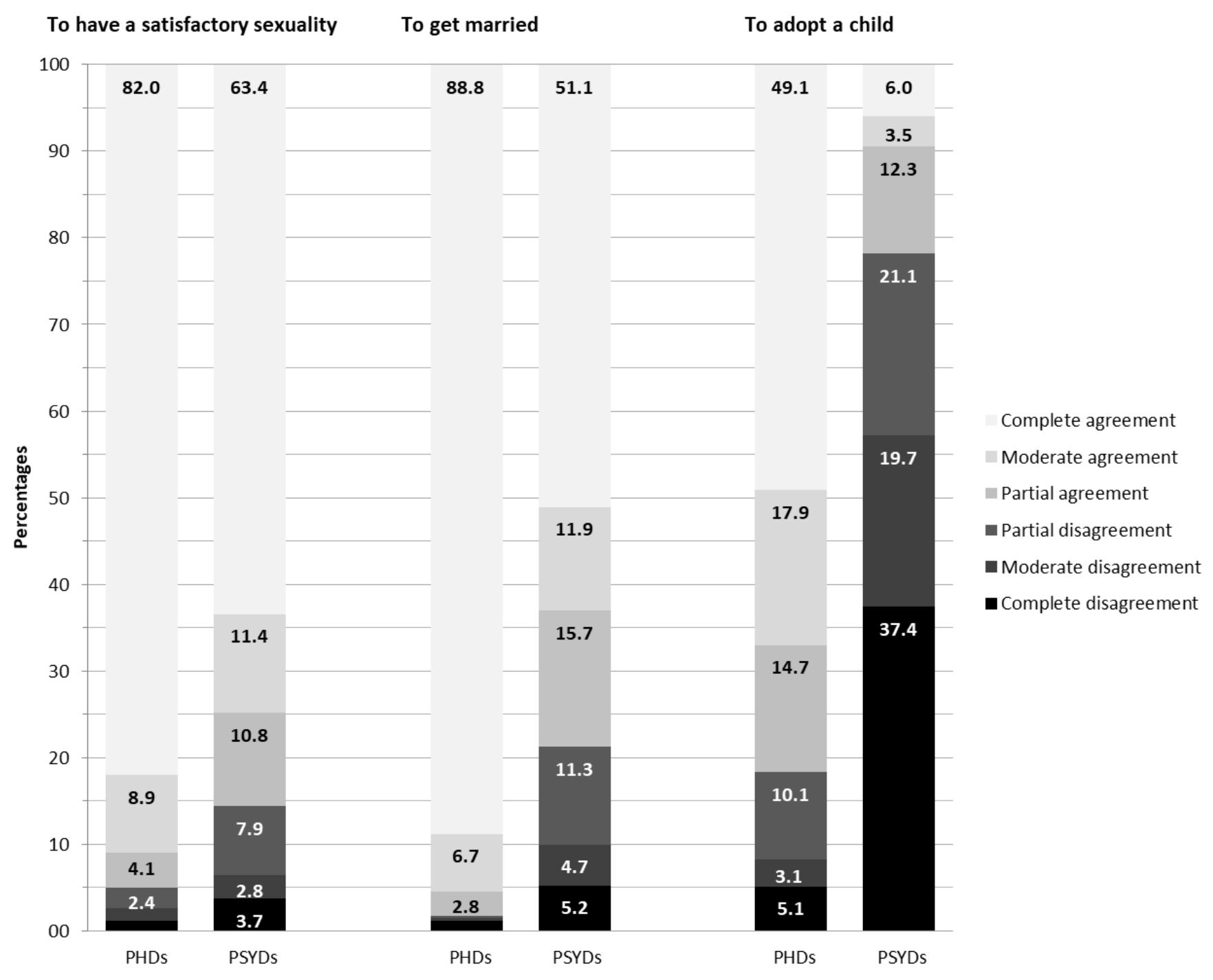

Figure 1. Distribution of responses inquiring agreement with the sexual rights of people with physical disabilities (PHDs) and Psychical disabilities (PSYDs) to have satisfactory sexuality, to get married, and to adopt a child. The light gray columns with black labels represent the agreement responses. The dark gray columns with white labels represent the disagreement responses. The complete disagreement is represented in black. Labels are presented only for response options chosen by at least $2 \%$ of participants.

\subsection{The right of PwPHDs and PwPSYDs to have satisfactory sexuality}

\subsubsection{Percentages of agreement and comparison between PwPHDs and PwPSYDs}

Overall, more than $85 \%$ of the sample declared in agreement with the right of PwDs to have satisfactory sexuality (Graph 1 ). Only $1.1 \%, 1.4 \%$, and $2.4 \%$ of participants answered being completely, moderately or mildly against it, while $4.1 \%, 8.9 \%$ and $82.0 \%$ declared mildly, moderately or completely in favor of it. A slightly lower number of respondents expressed complete, moderate or slight agreement with the right of PwPSYDs to have satisfactory sexuality $(63.4 \%, 11.4 \%$, and $10.8 \%$, respectively), while $7.9 \%, 2.8 \%$ and $3.7 \%$ were mildly, moderately or completely opposed. 
The Wilcoxon Signed-Ranks Test indicated that the median ranks for PwPHDs were statistically significantly higher than the median ranks for PwPSYDs $(Z=13.04 \mathrm{p}<.001)$.

3.1.2. Socio-demographic variables associated with agreement with PwPHDs's right to have satisfactory sexuality

The results of the univariate logistic regression analyses suggested the existence of an association between demographics, such as sex, education, occupation and relational status, and agreement with the SR of people with $\mathrm{PhD}$ to have satisfactory sexuality (table 2). None of the VIF exceeded 2.5. The multiple logistic regression analysis included all predictors and indicated that only positive associations between 'agreement' and sex were maintained, when taking into account other potential predictors. Women agreed in significantly higher percentages than men (96.1\% vs 92.5\%) with the right of PwPHDs to have satisfying sexuality (O.R. $=2.11 ; 95 \%$ C.I.: $1.11-4.01 ; \mathrm{p}=0.022$ ).

3.1.3. Socio-demographic variables associated with agreement with PwPSYDs's right to have satisfactory sexuality

The results of the univariate logistic regression analyses suggested the existence of an association between agreement with the right of people with PSYDs to have satisfactory sexuality and sex, religion, regional origin, occupational status, relational condition and level of education (table 2). None of the VIF exceeded 2.5. The multiple logistic regression analysis included all predictors and indicated that most of these associations maintained statistical significance. In particular, being female, atheist, graduate, employed or student and living with a partner were related to higher odds for agreement than being male (O.R. =1.55; 95\% C.I.: $1.03-2.35 ; \mathrm{p}=0.038)$, believer (O.R. $=1.82 ; 95 \%$ C.I.: $1.18-2.82 ; \mathrm{p}=0.007)$ or churchgoer (O.R. $=2.25 ; 95 \%$ C.I.: $1.3-3.89 ; \mathrm{p}=0.004)$, undergraduate (O.R. = 1.73; 95\% C.I.: $1.1-2.72 ; \mathrm{p}=0.019)$, unemployed (employed: O.R. = 1.92; 95\% C.I.: $1.18-3.11 ; \mathrm{p}=0.008$; student: O.R. $=2.47 ; 95 \%$ C.I.: $1.27-4.81 ; \mathrm{p}=0.008)$, or single (cohabitant: O.R. $=1.92 ; 95 \%$ C.I.: $1.06-3.48 ; \mathrm{p}=0.032 ;$ married: O.R. $=1.87 ; 95 \%$ C.I.: $1.11-3.17 ; \mathrm{p}=0.019)$, respectively, while regional origin resulted in an association that was bordering on statistical significance (O.R. $=1.59 ; 95 \%$ C.I.: $1-2.54 ; p=0.051)$.

\subsection{The right of PwPHDs and PwPSYDs to get married}

\subsubsection{Percentages of agreement and comparison between PwPHDs and PwPSYDs}

Overall, 98.3\% participants declared in agreement with the right of PwPHDs to marry, while $78.7 \%$ of them answered being favorable to marriage for PwPSYD (Graph 1). In particular, $88.8 \%$ participants expressed strong agreement with the possibility fot PwHDs to get married, while $6.7 \%$ and $2.8 \%$ declared moderately and mildly in favor, and only $1.7 \%$ expressed disagreement. A noticeable lower number of respondents expressed complete, moderate or slight agreement with the right of PwPSYDs to marry $(51.1 \%, 11.9 \%$, and $15.7 \%$, respectively), while $11.3 \%, 4.7 \%$ and $5.2 \%$ were mildly, moderately or completely opposed (Graph 1).

The Wilcoxon Signed-Ranks Test indicated that the median ranks for PwPHDs were statistically significantly higher than the median ranks for PwPSYDs $(Z=17.85 \mathrm{p}<.001)$. 3.3.2. Socio-demographic variables associated with agreement with PwPHDs's right to get married

3.3.2. Socio-demographic variables associated with agreement with PwPHDs's right to get married

The results of the logistic regression analyses are to interpret with caution, due to the extremely low number of people against marriage for PwPHDs in our sample (Table 3). Atheists/agnostics agreed in significantly higher percentages than churchgoers $(99.6 \%$ vs 95.9\%) with the right of PwPHDs to marry, and a positive significant association seemed to exist between 'agreement' and religiosity in multiple regression analysis (O.R. = 7.22; 95\% C.I.: 1.32 - 39.62; $\mathrm{p}=0.023$ ). 
3.3.3. Socio-demographic variables associated with agreement with PwPSYDs's right to get married

The results of the univariate logistic regression analyses suggested the existence of an association between agreement with the right of people with PSYDs to marry and all considered predictors, with the exception of provenance (table 3 ). None of the VIF exceeded 2.5. The multiple logistic regression analysis included all predictors and indicated that most of these associations maintained statistical significance in the multivariate model. In particular, being female, atheist/agnostic, post-graduate, student and non (completely) heterosexual were related to higher odds for agreement than being male (O.R. $=1.83$; 95\% C.I.: $1.28-2.63 ; \mathrm{p}=0.001)$, believer (O.R. $=1.47$; 95\% C.I.: $1.01-2.16 ; \mathrm{p}=$ $0.046)$ or churchgoer (O.R. $=2.62 ; 95 \%$ C.I.: $1.65-4.17 ; \mathrm{p}<0.001)$, undergraduate (O.R. $=$ 1.9; 95\% C.I.: $1.21-2.98 ; \mathrm{p}=0.005)$, unemployed (O.R. $=2.31 ; 95 \%$ C.I.: $1.2-4.43 ; \mathrm{p}=$ $0.012)$, or heterosexual (O.R. $=1.81 ; 95 \%$ C.I.: $1.13-2.88 ; \mathrm{p}=0.013)$.

\subsection{The right of PwPHDs and PwPSYDs to adopt a child}

\subsubsection{Percentages of agreement and comparison between PwPHDs and PwPSYDs}

The right of PwDs to adopt a child encountered the agreement of $71.7 \%$ of the sample, while $21.8 \%$ of respondents declared themselves in favor of the adoption of a child by the PwPSYDs (Graph 1). 5.1\%, 3.1\%, and 10.1\% of participants answered being completely, moderately or mildly opposed to this right for PwPHDs, while $14.7 \%, 17.9 \%$ and $49.1 \%$ declared mildly, moderately or completely in favor. A noticeable lower number of respondents expressed complete, moderate or slight agreement with the right of PwPSYDs adopt $(6.0 \%, 3.5 \%$, and $12.3 \%$, respectively), while $21.1 \%, 19.7 \%$ and $37.4 \%$ were mildly, moderately or completely opposed.

The Wilcoxon Signed-Ranks Test indicated that the median ranks for PwPHDs were statistically significantly higher than the median ranks for PwPSYDs $(Z=24.57 \mathrm{p}<.001)$.

3.4.2. Socio-demographic variables associated with agreement with PwPHDs's right to adopt a child

The results of the univariate logistic regression analyses suggested the existence of an association between education, religiosity, sexual orientation and relational status, and agreement with the right of people with PhD to adopt a child (table 4). In the multiple logistic regression analysis, indicated that positive associations were maintained between 'agreement' and education and sexual orientation, when taking into account other potential predictors. Post-graduates and non (completely) heterosexuals agreed in significantly higher percentages than undergraduates (O.R. $=1.84$; 95\% C.I.: $1.14-2.98$; $\mathrm{p}$ $=0.013)$ and heterosexual people (O.R. $=2.03 ; 95 \%$ C.I.: $1.26-3.27 ; \mathrm{p}=0.004)$ with the right of PwPHDs to adopt a child.

3.4.3. Socio-demographic variables associated with agreement with PwPSYDs's right to adopt a child

The results of the univariate logistic regression analyses suggested the existence of an association between agreement with the right of people with PSYDs to adopt a child and age, sexual orientation religion, and level of education (table 4). None of the VIF exceeded 2.5. The multiple logistic regression analysis included all predictors and indicated that religion and education maintained statistical significance in the multivariate model. Indeed, being post-graduate and atheist/agnostic were related to higher odds for agreement than being under-graduate (O.R. $=1.97 ; 95 \%$ C.I.: $1.26-3.08 ; \mathrm{p}=0.003)$, or churchgoer (O.R. $=2.28$; 95\% C.I.: $1.3-3.99 ; \mathrm{p}=0.004)$. 
Table 2. Socio-demographic features and percentages of agreement with the right of people with Physical and Psychical disabilities to have satisfactory sexuality: Frequencies (in percentages) and results of the univariate and multiple logistic regression analyses. Significant differences with respect to the reference are reported in bold.

\begin{tabular}{|c|c|c|c|c|c|c|c|c|c|c|c|}
\hline \multirow{3}{*}{\multicolumn{2}{|c|}{$\begin{array}{l}\text { Agreement with the right of people } \\
\text { with disabilities to have } \\
\text { satisfactory sexuality }\end{array}$}} & \multicolumn{5}{|c|}{ People with Physical Disabilities } & \multicolumn{5}{|c|}{ People with Psychical Disabilities } \\
\hline & & \multirow[b]{2}{*}{ Freq $\%$} & \multicolumn{2}{|l|}{ Univariate LR } & \multicolumn{2}{|l|}{ Multiple LR } & \multirow[b]{2}{*}{ Freq $\%$} & \multicolumn{2}{|l|}{ Univariate LR } & \multicolumn{2}{|l|}{ Multiple LR } \\
\hline & & & OR $(95 \% \mathrm{CI})$ & $\mathrm{p}$ & OR $(95 \%$ CI) & $\mathrm{p}$ & & OR $(95 \%$ CI) & $\mathrm{p}$ & OR $(95 \% \mathrm{CI})$ & $\mathrm{p}$ \\
\hline \multirow[t]{2}{*}{ Sex } & Male & 92.5 & - & - & - & - & 81.9 & - & - & - & - \\
\hline & Female & 96.1 & $1.99(1.11-3.58)$ & .022 & $2.11(1.11-4.01)$ & .022 & 87.1 & $1.5(1.03-2.19)$ & .034 & $1.55(1.03-2.35)$ & .038 \\
\hline \multirow[t]{3}{*}{ Age } & $18-29$ & 94.5 & - & - & - & - & 86.5 & - & - & - & - \\
\hline & $30-39$ & 95.0 & $1.09(.55-2.13)$ & .801 & $.76(.29-1.99)$ & .579 & 84.9 & $0.88(0.57-1.35)$ & .554 & $0.84(0.49-1.47)$ & .551 \\
\hline & 40 or more & 95.8 & $1.32(.63-2.78)$ & .458 & $1.40(.48-4.13)$ & .538 & 85.4 & $0.91(0.58-1.43)$ & .684 & $1.16(0.63-2.12)$ & .642 \\
\hline \multirow[t]{3}{*}{ Provenience } & North & 96.2 & - & - & - & - & 88.2 & - & - & - & - \\
\hline & Center & 94.3 & $.66(.33-1.33)$ & .242 & $.59(.28-1.24)$ & .164 & 86.0 & $0.82(0.53-1.28)$ & .382 & $0.74(0.46-1.19)$ & .221 \\
\hline & South and Islands & 94.4 & $.68(.33-1.41)$ & .298 & $.80(.37-2.01)$ & .584 & 81.4 & $0.59(0.38-0.90)$ & .016 & $0.63(0.39-1.00)$ & .051 \\
\hline \multirow[t]{3}{*}{ Instruction } & Undergraduate & 93.1 & - & - & - & - & 81.6 & - & - & - & - \\
\hline & Graduate & 96.9 & $2.35(1.15-4.80)$ & .019 & $1.91(.89-4.08)$ & .096 & 88.5 & $1.73(1.14-2.63)$ & .010 & $1.73(1.1-2.72)$ & .019 \\
\hline & Post-graduate & 94.8 & $1.36(.68-2.74)$ & .393 & $.89(.39-2.01)$ & .777 & 86.4 & $1.43(0.91-2.26)$ & .124 & $1.42(0.85-2.36)$ & .179 \\
\hline \multirow[t]{3}{*}{ Occupation } & Unemployed-retired & 92.5 & - & - & - & - & 76.9 & - & - & - & - \\
\hline & Employed & 96.3 & $2.10(1.00-4.41)$ & .050 & $2.16(0.97-4.78)$ & .058 & 86.8 & $1.97(1.26-3.09)$ & .003 & $1.92(1.18-3.11)$ & .008 \\
\hline & Student & 93.2 & $1.11(.49-2.52)$ & .804 & $0.95(0.34-2.67)$ & .924 & 88.3 & $2.28(1.29-4.05)$ & .005 & $2.47(1.27-4.81)$ & .008 \\
\hline \multirow[t]{2}{*}{ Heterosexual } & Yes & 94.9 & - & - & - & - & 84.5 & - & - & - & - \\
\hline & Not completely/no & 95.5 & $1.13(.57-2.24)$ & .736 & $1.44(0.66-3.15)$ & .361 & 88.9 & $1.47(0.94-2.29)$ & .094 & $1.35(0.82-2.22)$ & .241 \\
\hline Relational & Single/casual partners & 94.5 & - & - & - & - & 80.7 & - & - & - & - \\
\hline \multirow[t]{3}{*}{ status } & In a committed relationship & 97.9 & $2.33(1.05-5.16)$ & .037 & $2.64(0.8-8.75)$ & .112 & 87.3 & $1.64(1.03-2.63)$ & .037 & $1.52(0.93-2.48)$ & .094 \\
\hline & Cohabiting with partner & 96.5 & $3.89(1.32-11.47)$ & .014 & $1.86(0.69-5.04)$ & .220 & 90.0 & $2.15(1.23-3.76)$ & .007 & $1.92(1.06-3.48)$ & .032 \\
\hline & Married & 92.3 & $1.45(.71-2.94)$ & .306 & $0.82(0.36-1.87)$ & .637 & 86.1 & $1.49(0.93-2.38)$ & .099 & $1.87(1.11-3.17)$ & .019 \\
\hline \multirow[t]{3}{*}{ Religiosity } & Atheist/agnostic & 95.5 & - & - & - & - & 89.9 & - & - & - & - \\
\hline & Believer & 94.5 & $.81(.43-1.51)$ & .808 & $0.77(0.39-1.52)$ & .450 & 82.5 & $0.53(0.36-0.8)$ & .002 & $0.55(0.36-0.85)$ & .007 \\
\hline & Churchgoer & 93.3 & $.96(.40-2.30)$ & .918 & $0.97(0.38-2.47)$ & .945 & 79.7 & $0.44(0.27-0.73)$ & .001 & $0.44(0.26-0.77)$ & .004 \\
\hline
\end{tabular}


LR: Logistic regression model; Freq \%: percentages; OR: odds ratio; 95 \% CI: 95 \% confidence interval; -: reference value; Not completely/no: not-completely heterosexual, homosexual, bisexual or queer

Table 3. Socio-demographic features and percentages of agreement with the right of people with Physical and Psychical disabilities to get married: Frequencies (in percentages) and results of the univariate and multiple logistic regression analyses. Significant differences with respect to the reference are reported in bold.

Agreement with the right

of people with disabilities

to get married

Sex

Age

Female

18-29

30-39

40 or more

Provenience North

Center

South and Islands

Instruction

Undergraduate

Graduate

Post-graduate

Occupation

Unemployed-retired

Employed

Student

Heterosexual

\section{Not completely/no}

Relational

status

\section{Single/casual partners}

In a committed relationship

Cohabiting with partner

Married

Religiosity
People with Physical Disabilities People with Psychical Disabilities

\begin{tabular}{|c|c|c|c|c|c|c|c|c|c|}
\hline \multirow[b]{2}{*}{ Freq \% } & \multicolumn{2}{|l|}{ Univariate LR } & \multicolumn{2}{|l|}{ Multiple LR } & \multirow[b]{2}{*}{ Freq \% } & \multicolumn{2}{|l|}{ Univariate LR } & \multicolumn{2}{|l|}{ Multiple LR } \\
\hline & OR $(95 \%$ CI $)$ & $\mathrm{p}$ & OR $(95 \%$ CI $)$ & $\mathrm{p}$ & & OR $(95 \%$ CI $)$ & $\mathrm{p}$ & OR $(95 \%$ CI) & $\mathrm{p}$ \\
\hline 97.2 & - & - & - & - & 71.2 & - & - & - & - \\
\hline 98.7 & $2.22(0.85-5.82)$ & .104 & $2.05(0.71-5.9)$ & .183 & 81.8 & $1.82(1.32-2.51)$ & .000 & $1.83(1.28-2.63)$ & .001 \\
\hline 100.0 & - & - & - & - & 86.2 & - & - & - & - \\
\hline 97.6 & - & - & - & - & 76.3 & $0.52(0.35-0.77)$ & .001 & $0.62(0.37-1.03)$ & .066 \\
\hline 96.9 & $0.36(0.14-0.95)$ & .040 & $0.9(0.28-2.85)$ & .852 & 72.5 & $0.42(0.28-0.63)$ & .000 & $0.68(0.39-1.16)$ & .152 \\
\hline 97.9 & - & - & - & - & 78.7 & - & - & - & - \\
\hline 98.7 & $1.62(0.48-5.44)$ & .433 & $1.13(0.3-4.18)$ & .856 & 81.8 & $1.22(0.84-1.77)$ & .302 & $1.03(0.69-1.55)$ & .869 \\
\hline 98.1 & $1.11(0.36-3.42)$ & .861 & $0.96(0.28-3.27)$ & .952 & 75.1 & $0.82(0.56-1.18)$ & .276 & $0.76(0.51-1.14)$ & .182 \\
\hline 97.3 & - & - & - & - & 74.4 & - & - & - & - \\
\hline 98.7 & $2.15(0.71-6.48)$ & .174 & $1.45(0.42-4.99)$ & .557 & 80.6 & $1.43(1-2.03)$ & .048 & $1.35(0.91-1.99)$ & .134 \\
\hline 98.8 & $2.29(0.61-8.56)$ & .217 & $2.06(0.49-8.6)$ & .321 & 81.6 & $1.53(1.02-2.29)$ & .040 & $1.90(1.21-2.98)$ & .005 \\
\hline 96.6 & - & - & - & - & 73.5 & - & - & - & - \\
\hline 98.2 & $1.95(0.67-5.7)$ & .223 & $1.9(0.6-5.98)$ & .272 & 76.6 & $1.18(0.78-1.78)$ & .423 & $1.32(0.84-2.07)$ & .224 \\
\hline 99.5 & $7.22(0.83-62.45)$ & .073 & $4.49(0.42-47.69)$ & .213 & 88.8 & $2.87(1.63-5.07)$ & .000 & $2.31(1.2-4.43)$ & .012 \\
\hline 97.8 & - & - & - & - & 75.5 & - & - & - & - \\
\hline 99.6 & $5.42(0.72-41.11)$ & .102 & $2.37(0.27-20.54)$ & .434 & 88.5 & $2.49(1.63-3.83)$ & .000 & $1.81(1.13-2.88)$ & .013 \\
\hline 97.5 & - & - & - & - & 80.0 & - & - & - & - \\
\hline 99.6 & $6.52(0.8-53.37)$ & .080 & $4.96(0.58-42.2)$ & .143 & 80.4 & $1.02(0.67-1.56)$ & .910 & $0.81(0.52-1.28)$ & .373 \\
\hline 99.5 & $4.76(0.58-39)$ & .146 & $3.39(0.38-29.87)$ & .271 & 83.7 & $1.28(0.79-2.08)$ & .312 & $1.12(0.66-1.88)$ & .680 \\
\hline 96.6 & $0.72(0.26-2.03)$ & .538 & $1.18(0.39-3.63)$ & .768 & 71.4 & $0.63(0.42-0.94)$ & .023 & $0.93(0.59-1.47)$ & .765 \\
\hline 99.6 & - & - & - & - & 84.9 & - & - & - & - \\
\hline
\end{tabular}




\begin{tabular}{lllllllllll} 
Believer & 97.5 & $\mathbf{0 . 1 7 ( 0 . 0 4 - 0 . 7 9 )}$ & .024 & $0.22(0.04-1.08)$ & .062 & 76.7 & $\mathbf{0 . 5 9 ( 0 . 4 1 - 0 . 8 3 )}$ & $\mathbf{. 0 0 3}$ & $\mathbf{0 . 6 8 ( 0 . 4 6 - 0 . 9 9 )}$ & $\mathbf{. 0 4 6}$ \\
Churchgoer & 95.9 & $\mathbf{0 . 1 ( 0 . 0 2 - 0 . 5 1 )}$ & .006 & $\mathbf{0 . 1 4}(\mathbf{0 . 0 3 - 0 . 7 6 )}$ & .023 & 64.2 & $\mathbf{0 . 3 2 ( 0 . 2 1 - 0 . 4 9 )}$ & $\mathbf{. 0 0 0}$ & $\mathbf{0 . 3 8 ( 0 . 2 4 - 0 . 6 1 )}$ & $\mathbf{. 0 0 0}$ \\
\hline
\end{tabular}

LR: Logistic regression model; Freq \%: percentages; OR: odds ratio; 95 \% CI: 95 \% confidence interval; -: reference value; Not completely/no: not-completely heterosexual, homosexual, bisexual or queer

Table 4. Socio-demographic features and percentages of agreement with the right of people with Physical and Psychical disabilities to adopt a child: Frequencies (in percentages) and results of the univariate and multiple logistic regression analyses. Significant differences with respect to the reference are reported in bold.

\begin{tabular}{|c|c|c|c|c|c|c|c|c|c|c|c|}
\hline \multirow{3}{*}{\multicolumn{2}{|c|}{$\begin{array}{l}\text { Agreement with the right of people } \\
\text { with disabilities to adopt a child }\end{array}$}} & \multicolumn{5}{|c|}{ People with Physical Disabilities } & \multicolumn{5}{|c|}{ People with Psychical Disabilities } \\
\hline & & \multirow[b]{2}{*}{ Freq \% } & \multicolumn{2}{|l|}{ Univariate LR } & \multicolumn{2}{|l|}{ Multiple LR } & \multirow[b]{2}{*}{ Freq \% } & \multicolumn{2}{|l|}{ Univariate LR } & \multicolumn{2}{|l|}{ Multiple LR } \\
\hline & & & OR (95\% CI) & $\mathrm{p}$ & OR $(95 \% \mathrm{CI})$ & $\mathrm{p}$ & & OR $(95 \% \mathrm{CI})$ & $\mathrm{p}$ & OR $(95 \% \mathrm{CI})$ & $\mathrm{p}$ \\
\hline \multirow[t]{2}{*}{ Sex } & Male & 81.1 & - & - & - & - & 19.9 & - & - & - & - \\
\hline & Female & 81.9 & $1.05(0.74-1.51)$ & .771 & $0.99(0.67-1.46)$ & .949 & 22.5 & $1.17(0.83-1.65)$ & .371 & $1.05(0.73-1.52)$ & .800 \\
\hline \multirow[t]{3}{*}{ Age } & $18-29$ & 81.6 & - & - & - & - & 25.9 & - & - & - & - \\
\hline & $30-39$ & 84.0 & $1.19(0.8-1.76)$ & .402 & $1.29(0.77-2.14)$ & .332 & 20.7 & $0.75(0.52-1.07)$ & .111 & $0.84(0.53-1.34)$ & .465 \\
\hline & 40 or more & 79.1 & $0.85(0.58-1.26)$ & .426 & $1.17(0.68-2.00)$ & .576 & 18.1 & $0.63(0.43-0.93)$ & .020 & $0.83(0.49-1.40$ & .486 \\
\hline \multirow{3}{*}{ Provenience } & North & 82.6 & - & - & - & - & 21.8 & - & - & - & - \\
\hline & Center & 84.1 & $1.12(0.75-1.66)$ & .593 & $1.04(0.68-1.58)$ & .853 & 23.9 & $1.13(0.79-1.6)$ & .511 & $1.07(0.74-1.55)$ & .712 \\
\hline & South and Islands & 77.7 & $0.74(0.5-1.08)$ & .121 & $0.74(0.49-1.11)$ & .144 & 19.3 & $0.86(0.58-1.27)$ & .444 & $0.86(0.58-1.29)$ & .479 \\
\hline \multirow[t]{3}{*}{ Instruction } & Undergraduate & 77.4 & - & - & - & - & 17.8 & - & - & - & - \\
\hline & Graduate & 82.6 & $1.39(0.96-2)$ & .081 & $1.37(0.92-2.04)$ & .118 & 22.8 & $1.36(0.94-1.97)$ & .098 & $1.43(0.97-2.11)$ & .074 \\
\hline & Post-graduate & 86.0 & $1.79(1.15-2.78)$ & .009 & $1.84(1.14-2.98)$ & .013 & 25.6 & $1.59(1.07-2.37)$ & .023 & $1.97(1.26-3.08)$ & .003 \\
\hline \multirow[t]{3}{*}{ Occupation } & Unemployed-retired & 77.6 & - & - & - & - & 21.8 & - & - & - & - \\
\hline & Employed & 82.1 & $1.33(0.86-2.06)$ & .206 & $1.14(0.71-1.81)$ & .590 & 19.5 & $0.87(0.56-1.35)$ & .539 & $0.82(0.51-1.30)$ & .395 \\
\hline & Student & 83.5 & $1.46(0.86-2.5)$ & .162 & $1.51(0.82-2.78)$ & .186 & 28.6 & $1.44(0.88-2.37)$ & .147 & $1.51(0.87-2.65)$ & .146 \\
\hline \multirow[t]{2}{*}{ Heterosexual } & Yes & 79.2 & - & - & - & - & 20.3 & - & - & - & - \\
\hline & Not completely/no & 89.3 & $2.19(1.41-3.42)$ & .001 & $2.03(1.26-3.27)$ & .004 & 26.3 & $1.41(1-1.97)$ & .048 & $1.16(0.8-1.68)$ & .430 \\
\hline \multirow{2}{*}{$\begin{array}{l}\text { Relational } \\
\text { status }\end{array}$} & Single/casual partners & 79.3 & - & - & - & - & 20.4 & - & - & - & - \\
\hline & In a committed relationship & 83.1 & $1.28(0.83-1.98)$ & .261 & $1.28(0.82-2.01)$ & .280 & 21.9 & $1.1(0.73-1.66)$ & .653 & $0.98(0.64-1.50)$ & .917 \\
\hline
\end{tabular}




\begin{tabular}{|c|c|c|c|c|c|c|c|c|c|c|c|}
\hline \multirow{5}{*}{ Religiosity } & Cohabiting with partner & 87.9 & $1.90(1.13-3.19)$ & .016 & $1.7(0.98-2.96)$ & .061 & 26.8 & $1.44(0.93-2.21)$ & .100 & $1.42(0.89-2.26)$ & .145 \\
\hline & Married & 78.2 & $0.93(0.61-1.42)$ & .749 & $1.05(0.66-1.68)$ & .835 & 19.3 & $0.94(0.61-1.44)$ & .770 & $1.29(0.79-2.10)$ & .314 \\
\hline & Atheist/agnostic & 85.6 & - & - & - & - & 26.1 & - & - & - & - \\
\hline & Believer & 77.6 & $0.58(0.41-0.83)$ & .003 & $0.72(0.49-1.05)$ & .089 & 20.2 & $0.72(0.52-1)$ & .050 & $0.79(0.55-1.12)$ & .181 \\
\hline & Churchgoer & 79.7 & $0.66(0.41-1.07)$ & .092 & $0.88(0.53-1.47)$ & .623 & 12.2 & $0.39(0.23-0.67)$ & .001 & $0.44(0.25-0.77)$ & .004 \\
\hline
\end{tabular}

LR: Logistic regression model; Freq \%: percentages; OR: odds ratio; 95 \% CI: 95 \% confidence interval; -: reference value; Not completely/no: not-completely

heterosexual, homosexual, bisexual or queer

\begin{tabular}{|c|c|c|c|c|c|c|c|c|}
\hline $1.90(1.13-3.19)$ & .016 & $1.7(0.98-2.96)$ & .061 & 26.8 & $1.44(0.93-2.21)$ & .100 & $1.42(0.89-2.26)$ & .145 \\
\hline $0.93(0.61-1.42)$ & .749 & $1.05(0.66-1.68)$ & .835 & 19.3 & $0.94(0.61-1.44)$ & .770 & $1.29(0.79-2.10)$ & .314 \\
\hline - & - & - & - & 26.1 & - & - & - & - \\
\hline $0.58(0.41-0.83)$ & .003 & $0.72(0.49-1.05)$ & .089 & 20.2 & $0.72(0.52-1)$ & .050 & $0.79(0.55-1.12)$ & .181 \\
\hline $0.66(0.41-1.07)$ & .092 & $0.88(0.53-1.47)$ & .623 & 12.2 & $0.39(0.23-0.67)$ & .001 & $0.44(0.25-0.77)$ & .004 \\
\hline
\end{tabular}

(1)

(1)

(1)

(a)

Preprints (vwiv.preprints.org) | NOT PEER-REVIEWED | Posted: 2 December 2021 


\section{Discussion}

To our knowledge, this is the first published research to inquire the levels of agreement with the SPRs of PwDs in the Italian general population and the socio-demographic variables which may associate to positive or negative attitudes.

The results of this study indicate that in very large majority Italians declared themselves in agreement with the right of PwPHDs to have satisfactory sexuality and to marry, and most inclined to express agreement with their right to adopt a child, albeit to a lesser extent. Consistent with other research, the percentage of people who disagreed with these SPRs when related to PwPSYDs was significantly higher[11], and almost 80\% of the sample declared against the right for adoption for PwPSYDs. Indeed, the sexuality of PwPSYDs was found to be judged as less appropriate than that of persons without any disability or with physical disabilities. It was observed that PwPSYDs are subjected to stereotypes of inability of judgment and control, unpredictability and danger, resulting in false beliefs about unsafe sex, promiscuity or abuse[11]. This may also explain our findings, even we did not investigate beliefs or stereotypes associated with recognition.

Coherently with other studies[18,19], opinions concerning the possibility for PwDs to adopt a child were more unfavorable than those related to sexuality and marriage, confirming that participants considered this aspect to be more complex and to, perhaps, to have implications beyond the mere SPRs of the individuals and to require abilities that many would judge to be too complex to be carried on by PwDs, and, in particular, by PwPSYDs. Different from another study by Cuskelly and Gilmore[18], who observed less favorable, yet still substantially positive, attitudes about parenting in PwPSYDs, Italian respondents declared for the most tendentially or completely against PwPSYDs being allowed to adopt a child. This difference could also be amplified by the fact that the present research requires a specific opinion related to adoption and not on the general possibility of being parents.

Consistent with other research, women appeared to be more supportive of PwDs' right to have satisfactory sexuality and of PwPSYDs' right to marry than men, while no differences between genders were observed about parenting [22,23].

Regarding socio-demographic variables, our data revealed that religion was a strong predictor of negative attitudes in most analyses, with churchgoers as the most uncompromising category. Indeed, religious culture, with a "religious ethical model" has contributed in the past to the structuring of "false myths" about disability, supporting the opinion that a disabled body or mind is an indication of an inner (moral) ugliness (sin); therefore, the myth of physical perfection that recalls purity and divine goodness, of very ancient memory, is very often found at the basis of prejudices on the causes of the impairment[6].

We found also a relationship between the level of education and the presence of agreement. In general, we observed that undergraduates tended to express more disagreement than graduates and post-graduates with SPRs of PwDs, and that post-graduates tended to agree in slightly higher percentages than graduates (with the exception of items relating to satisfactory sexuality). Other research revealed that students and professionals who had frequent contact with PwPSYDs generally had more negative attitudes compared to those who had less experience with them [35]. Even if in our sample medical doctors and psychologists represented up to $44.4 \%$ of post-graduates, our data appear to be inconsistent with the results of these researches. However, it should be noted that our survey did not require participants to specify whether their work involved contact with (or care of) PwDs. For this reason, it is possible that our sample included both people who had frequent contact with PwDs and people who had rare or absent relationships with them.

In some comparisons we observed that the proportion of people in agreement with the SPRs of the PwDs decreased with increasing age. However, in most univariate and multivariate analyses age did not appear to be a significant predictor of agreement, con- 
trary to what has been reported in some literature, which indicated age as an important predictor of negative attitudes towards the sexuality of PwD and, in particular, of those with intellectual disabilities. In any case, it is necessary to consider that our sample was mainly constituted by young people. Therefore, middle-aged and elderly people could be under-represented.

Sexual orientation was significant in predicting attitudes towards marriage and adoption, with not completely heterosexuals agreeing in a significantly higher percentage than heterosexuals ( $88.5 \%$ vs $75.5 \%$ ) to these SPRs. To our knowledge, there are no other studies that have investigated sexual orientation as a predictor for agreement with the SPRs of PwDs. We can hypothesize that, given that in the period in which the survey was administered the question of the "Zan" law was much debated, non-heterosexual people were also much more sensitive to the issues of legitimizing unconventional couples or parenting for minorities.

Our study presents some strengths and many limitations. As abovementioned, the main limitations concern the poor representativeness of the enrolled sample, being composed mainly of women, young people and graduates, and in high percentages by healthcare workers, therefore limiting the validity of this research. In any case, most of the literature on this topic derives from studies enrolling limited convenience samples of a few tens or hundreds of participants, mostly recruited among relatives, students or care-providers of PwDs. For this reason, even if not perfectly representative of the Italian population, our data fit into a line of research whose results tend to be hampered by selection bias.

Other limitations concern having included a limited number of variables among predictors. It is possible to hypothesize that people's level of agreement may be associated with other factors, e.g. having a relative with physical/psychical disability, or being pending adoption. We can also hypothesize that people were more sensitized to these topics, since they were often discussed in politics and media. However, it is not straightforward that greater exposure may have implied greater agreement.

A strength of our research is the fact that it is the first Italian study to have evaluated the opinions of people in the community regarding the civil and sexual rights of PwDs. Until now, to our knowledge, there was no Italian data relating to the topic.

Another strength is represented by the sample size. A sample of almost a thousand people is numerically very consistent and definitely higher than most of the works published so far on the topic. Although the results on the levels of agreement expressed by the entire sample must be interpreted with caution due to the aforementioned limitations, the sample size allowed to make predictions about the effect of different socio-demographic variables on agreement. Our data may therefore represent a useful background for more rigorous studies and interventions aimed at information and training campaigns on the issues of civil and sexual rights of minorities.

\section{Conclusions}

Although its limitations, this study has important implications regarding the SPRs of PwDs in Italy. Firstly, even if quite positive opinions were expressed in most answers, important work is needed to overcome the cultural barriers that prevent PwDs from fully exercising their rights, in particular the right to adopt a child. Second, our data confirmed that PwPSYDs are more discriminated than PwPHIDs. Actions are needed to overcome the prejudice and stigma towards them. Lastly, evidence is shown that certain characteristics of the population affect the level of recognition of PwDs' rights, in particular having strong religious beliefs is related to lower recognition. Also, male sex, higher age and lower education contributed in some analyses to outline the more uncompromising profiles. Other research demonstrated that specific training on sex and disability can lead to more positive attitudes related to their SPRs [22]. For this reason, it is necessary to 
work specifically on populations with the highest risk factors for uncompromising attitudes, focusing efforts where possible on improving knowledge and overcoming stereotypes.

Author Contributions: Conceptualization: SGDS, MC, MS, SE; methodology: SGDS, MC, MS.; software: SGDS; validation, MC and MS; formal analysis: SGDS; investigation: SGDS, MC, MS, VF, CM, CN, CR; data management, SGDS; writing-original draft preparation, SGDS, MC, MS, GRG.; writing-review and editing, VF, CM, CN, CR, SE; supervision, MS and SE; All authors have read and agreed to the published version of the manuscript.

Funding: This research received no external funding.

Institutional Review Board Statement: The study was conducted according to the guidelines of the Declaration of Helsinki, and approved by the Scientific Committee of the Italian Federation of Sexology.

Informed Consent Statement: An opt-in approach was used in this research. Informed consent was requested upon fulfillment of the online survey. "I Agree" button allowed participants to click and begin answering the questionnaire, in order to collect their data online. If they do not agree to participate the study, they have the option to click an "I Do Not Agree" button so that their data was not submitted and collected online.

Conflicts of Interest: The authors declare no conflict of interest

\section{References}

1. Carroll, A. World report on disability. Ir. Med. J. 2012, 105, 1-23, doi:10.1111/j.1741-1130.2011.00320.x.

2. United Nations (2006) Convention on the Rights of Persons with Disabilities and Optional Protocol. Available online: https://www.un.org/disabilities/documents/convention/convoptprot-e.pdf (accessed on Sep 28, 2021).

3. Devkota, H.R.; Kett, M.; Groce, N. Societal attitude and behaviours towards women with disabilities in rural Nepal: Pregnancy, childbirth and motherhood. BMC Pregnancy Childbirth 2019, 19, 1-13, doi:10.1186/s12884-019-2171-4.

4. World Health Organization (2015) Sexual health, human rights and the law. Available online: https://apps.who.int/iris/bitstream/handle/10665/175556/9789241564984_eng.pdf (accessed on Sep 28, 2021).

5. Brodwin, M.G.; Frederick, P.C. Sexuality and societal beliefs regarding persons living with disabilities. J. Rehabil. 2010, 76, $37-41$.

6. Stone, S.D. The Myth of Bodily Perfection. Disabil. Soc. 1995, 10, 413-424, doi:10.1080/09687599550023426.

7. Shakespeare, Tom, Gillespie-Sells, Kath, Davies, D. The sexual Politics of Disability: Untold Desires.; Cassell, Ed.; 1996;

8. Milligan, M.S.; Neufeldt, A.H. The myth of asexuality: A survey of social and empirical evidence. Sex. Disabil. 2001, 19, 91109, doi:10.1023/A:1010621705591.

9. Ganle, J.K.; Baatiema, L.; Quansah, R.; Danso-Appiah, A. Barriers facing persons with disability in accessing sexual and reproductive health services in sub-Saharan Africa: A systematic review. PLoS One 2020.

10. Addlakha, R.; Price, J.; Heidari, S. Disability and sexuality: Claiming sexual and reproductive rights. Reprod. Health Matters 2017, 25, 4-9, doi:10.1080/09688080.2017.1336375.

11. Hasson-Ohayon, I.; Hertz, I.; Vilchinsky, N.; Kravetz, S. Attitudes toward the sexuality of persons with physical versus psychiatric disabilities. Rehabil. Psychol. 2014, 59, 236-241, doi:10.1037/a0035916.

12. McGuire, B.E.; Bayley, A.A. Relationships, sexuality and decision-making capacity in people with an intellectual disability. Curr. Opin. Psychiatry 2011, 24, 398-402, doi:10.1097/YCO.0b013e328349bbcb.

13. Price, J. The Seeds of a Movement - Disabled Women and their Struggle to Organize. Toronto Assoc. Women's Rights 2011, $1-15$.

14. Giami, A.; Humbert, C.; Laval, D. L'ange et la bête: Représentations de la sexualité des handicapés mentaux chez les parents et les éducateurs.; Editions de CTNERHI: Paris, 1983; 
15. Ditchman, N.; Kosyluk, K.; Lee, E.J.; Jones, N. How stigma affects the lives of people with intellectual disabilities: An overview. In Intellectual Disability and Stigma: Stepping Out from the Margins; Palgrave Macmillan/Springer Nature., 2016; pp. 31-47 ISBN 9781137524997.

16. Ditchman, N.; Easton, A.B.; Batchos, E.; Rafajko, S.; Shah, N. The Impact of Culture on Attitudes Toward the Sexuality of People with Intellectual Disabilities. Sex. Disabil. 2017, 35, 245-260, doi:10.1007/s11195-017-9484-x.

17. World Health Organization (2014) Eliminating forced, coercive and otherwise involuntary sterilization. Available online: www.who.int/reproductivehealth (accessed on Sep 29, 2021).

18. Cuskelly, M.; Gilmore, L. Attitudes to Sexuality Questionnaire (Individuals with an Intellectual Disability): Scale development and community norms. J. Intellect. Dev. Disabil. 2007, 32, 214-221, doi:10.1080/13668250701549450.

19. Cuskelly, M.; Bryde, R. Attitudes towards the sexuality of adults with an intellectual disability: Parents, support staff, and a community sample. J. Intellect. Dev. Disabil. 2004, 29, 255-264, doi:10.1080/13668250412331285136.

20. Meaney-Tavares, R.; Gavidia-Payne, S. Staff characteristics and attitudes towards the sexuality of people with intellectual disability. J. Intellect. Dev. Disabil. 2012, doi:10.3109/13668250.2012.701005.

21. Gilmore, L.; Chambers, B. Intellectual disability and sexuality: Attitudes of disability support staff and leisure industry employees. J. Intellect. Dev. Disabil. 2010, doi:10.3109/13668250903496344.

Pebdani, R.N. Attitudes of Group Home Employees Towards the Sexuality of Individuals with Intellectual Disabilities. Sex. Disabil. 2016, doi:10.1007/s11195-016-9447-7.

23. Hunt, X.; Carew, M.T.; Braathen, S.H.; Swartz, L.; Chiwaula, M.; Rohleder, P. The sexual and reproductive rights and benefit derived from sexual and reproductive health services of people with physical disabilities in South Africa: Beliefs of non-disabled people. Reprod. Health Matters 2017, 25, 66-79, doi:10.1080/09688080.2017.1332949.

24. Trudel, G.; Desjardins, G. Staff reactions toward the sexual behaviors of people living in institutional settings. Sex. Disabil. 1992, doi:10.1007/BF01102283.

25. Saxe, A.; Flanagan, T. Factors that impact support workers' perceptions of the sexuality of adults with developmental disabilities: A quantitative analysis. Sex. Disabil. 2014, 32, 45-63, doi:10.1007/s11195-013-9314-8.

26. Bazzo, G.; Nota, L.; Soresi, S.; Ferrari, L.; Minnes, P. Attitudes of social service providers towards the sexuality of individuals with intellectual disability. J. Appl. Res. Intellect. Disabil. 2007, doi:10.1111/j.1468-3148.2006.00308.x.

27. Sankhla, D.; Theodore, K. British Attitudes Towards Sexuality in Men and Women with Intellectual Disabilities: A Comparison Between White Westerners and South Asians. Sex. Disabil. 2015, 33, 429-445, doi:10.1007/s11195-015-9423-7.

28. Morales, G.E.M.; Ramirez, E.O.L.; Esterle, M.; Sastre, M.T.M.; Mullet, E. Judging the acceptability of sexual intercourse among people with learning DISABILities: A Mexico-france comparison. Sex. Disabil. 2010, doi:10.1007/s11195-010-9147-7.

29. Carew, M.T.; Braathen, S.H.; Hunt, X.; Swartz, L.; Rohleder, P. Predictors of negative beliefs toward the sexual rights and perceived sexual healthcare needs of people with physical disabilities in South Africa. Disabil. Rehabil. 2020, 42, 3664-3672, doi:10.1080/09638288.2019.1608323.

30. Camera dei Deputati XVIII Legislatura - Lavori - Progetti di legge - Scheda del progetto di legge. Available online: https://www.camera.it/leg18/126?tab=\&leg=18\&idDocumento=0569 (accessed on Sep 29, 2021).

31. Parlamento Italiano (2021) Disegno di legge S. 2005 - 18 ${ }^{\mathrm{a}}$ Legislatura. Available online: https://www.senato.it/leg/18/BGT/Schede/Ddliter/53457.htm (accessed on Nov 23, 2021).

32. Casadio, G. Oltre trenta piazze per rilanciare il ddl Zan. Scintille tra Pd e IV. La Repubblica. Available online: https://www.repubblica.it/politica/2021/10/31/news/ddl_zan_pd_italia_viva-324413430/(accessed on Nov 23, 2021).

33. Silvaggi, M.; Eleuteri, S.; Colombo, M.; Fava, V.; Malandrino, C.; Simone, S.; Nanini, C.; Rossetto, C.; Di Santo, S.G. Attitudes towards the sexual rights of LGB people: Factors involved in recognition and denial. Sexologies 2019, doi:10.1016/j.sexol.2019.06.004.

34. Silvaggi, M.; Di Santo, S.G.; Artioli, C.; Colombo, M.; Fava, V.; Malandrino, C.; Melis, I.; Nanini, C.; Rossetto, C.; Simone, S.; 
et al. HP-02-005 Sexual rights of minorities in Italy: A snapshot of reality and sociodemographic characteristics involved in the recognition and denial. J. Sex. Med. 2017, doi:10.1016/j.jsxm.2017.03.033.

35. Franco, D.G.; Cardoso, J.; Neto, I. Attitudes towards affectivity and sexuality of people with intellectual disability. Sex. Disabil. 2012. 